\title{
Analysis of Fracture Mechanisms and Surface Quality in Drilling of Composite Materials
}

\author{
J. Sedláček ${ }^{1, a}$ and A. Humár ${ }^{1, b}$ \\ ${ }^{1}$ Brno University of Technology, Faculty of Mechanical Engineering, Institute of Manufacturing \\ Technology, Brno, Czech Republic \\ aysedla10@fme.vutbr.cz, ${ }^{b}$ humar@fme.vutbr.cz \\ The aim of this work is to clarify the interaction mechanisms between the drilling tool and material \\ Drilling tests were carried out on glass/polyester and carbon/epoxy composites using different twist \\ drills. The cutting tools and machined surfaces were examined by optical microscopy, scanning \\ microscopy and surface profilometry to study composite damage and tool wear. Among the defects \\ caused by drilling, delamination appears to be the most critical and may occurs at both the entrance \\ and exit planes. A prediction model of thrust force for drilling without delamination is proposed.
}

Keywords: composite materials, delamination, surface quality, drilling, tool wear.

Introduction. Machining of composite materials is a rather complex task owing to its heterogeneity, heat sensitivity, and to the fact that reinforcements are extremely abrasive. Drilling is a frequently practiced machining process in industry owing to the need for component assembly in mechanical pieces and structures. On the other hand, drilling of laminate composite materials is significantly affected by the tendency of these materials to delaminate and the fibers to pull from the matrix under the action of machining forces (thrust force and torque).

Delamination Analysis. Delamination occurs along the fiber direction and develops in two phases: the chisel edge action phase and the cutting edge action phase. The first phase begins when the thrust force of the chisel edge into the exit surface reaches a critical value and ends when the chisel edge just penetrates the plate. By examining the photographs of exit surfaces and finished workpieces, it was found that the chisel edge has a strong effect on the formation of delamination. First a small bulge emerges in the vicinity of the drilling axis and then it develops along the fiber direction of the exit surface. When the bulge grows to a certain degree, the surface layer splits open, the chisel edge penetrates and the second (cutting edge action) phase starts. The delamination damage initiated in the first phase further develops due to the continuous pushing and twisting of the cutting edge. The chisel edge cuts the workpiece material with a large negative rake angle and generates over $50 \%$ of the thrust force. Thus the chisel edge plays a key role [1].

Delamination Model for Push-Out at Exit. A simple model for predicting thrust levels that will induce "push-out at exit" or "peel-up at entrance" delaminations has been proposed [2-4]. The delaminated area is assumed to be circular, and uncut portion is modeled as an isotropic circular plate clamped on its contour (Fig. 1). Drilling and fiber directions are shown in Fig. 2. The equation of energy balance can by expressed as follows, using the linear elastic fracture mechanics (assuming Mode I crack propagation)

$$
G d A=F d X-d U
$$

where $G$ is the energy release rate per unit area, $d A$ is the increase in the area of delamination crack, $F$ is the thrust force, $X$ is displacement of the drill, measured from position at which delamination started, and $U$ is the stored strain energy. Note that 


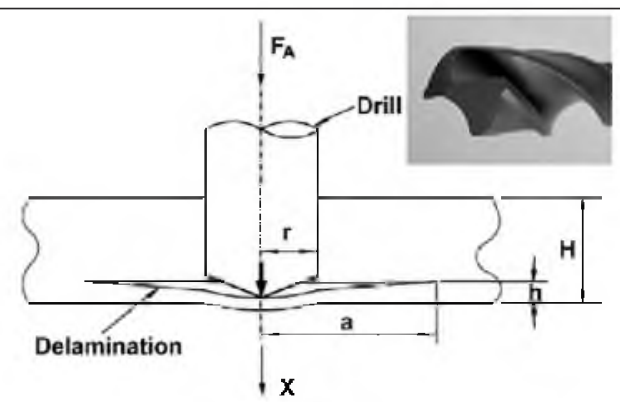

Fig. 1

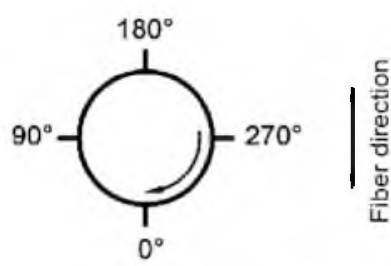

Fig. 2

Fig. 1. Delamination scheme: plate with clamped contour.

Fig. 2. Convention for drilling and fiber directions: arrow indicates the direction of tool rotation.

$$
d A=\pi(a+d a)(a+d a)-\pi a^{2}=2 \pi a d a
$$

where $a$ is the radius of delamination. For a circular plate with clamped ends subjected to a concentrated load, the stored strain energy $U$ is

$$
U=\frac{8 \pi M X^{2}}{a^{2}}
$$

where $M$ is flexural rigidity of plate under drill and is determined from thin plate theory or also called Kirchhoff plate theory as follows

$$
M=\frac{E h^{3}}{12\left(1-v^{2}\right)},
$$

where $E$ is the modulus of elasticity and $v$ is the Poisson's ratio for isotropic materials. The displacement $X$ in Eqs. (1) and (3) is given by

$$
X=\frac{F a^{2}}{16 \pi M} \text {. }
$$

using $a, F$, and $M$ according to [3]. After substitution of above-mentioned equations into Eq. (1), the energy balance of systems can be written as

$$
2 G \pi a=F \frac{d X}{d a}-\frac{d U}{d a}=F \frac{d}{d a} \frac{F a^{2}}{16 \pi M}-\frac{d}{d a} \frac{F^{2} a^{2}}{32 \pi M}=\frac{F^{2} a}{16 \pi M} .
$$

Hence, the critical thrust force for crack propagation (as function of the uncut thickness $h$ ) in case of the unidirectional orthotropic fiber composites is expressed as follows

$$
F_{A}(h)=\pi \sqrt{32 M G_{\mathrm{Ic}}}=\pi \sqrt{\frac{8 G_{\mathrm{Ic}} E_{2} h^{3}}{3\left(1-v_{21}^{2}\right)}} .
$$

Note that $E_{2}$ is the modulus of elasticity across the fiber direction, $v_{21}$ is the minor Poisson's ratio, and $G_{\mathrm{Ic}}$ is the interlaminar critical energy release rate (crack driving force) in Mode I loading. 
Tool Wear and Its Effect on Delamination. Among the possible wear mechanisms, which include adhesion, diffusion, oxidation, plastic deformation and brittle fracture, only abrasion and sometimes adhesion are of significance for cutting of composites [5]. Glass fiber-reinforced plastic (GFRP) made by pultrusion, (polyester matrix, 70\% glass volume, thickness $9.5 \mathrm{~mm}$ ) and drills made from different cutting materials were used for the wear tests.

The wear intensity of high-speed steel drills has been very high when drilling of GFRP, as it was expected. The width of facet at the drill major flank reached value $V B=1.33 \mathrm{~mm}\left(v_{c}=31.7 \mathrm{~m} / \mathrm{min}\right.$, Fig. 3a) for non-coated drill and a value $V B=1.04 \mathrm{~mm}$ $\left(v_{c}=35.2 \mathrm{~m} / \mathrm{min}\right.$, Fig. $3 b$ ) for coated drill, after about two minutes (102 s) of work time. It is of interest that the wear of high-speed steel drill is very high along all the length of the main cutting edge, even near of the centre of drill, where the cutting speed is very low. This fact confirms the very high abrasive effect of glass fibers in the wear process of the cutting tool when machining of GFRP. The values of torque have increased approximately 2.5 times in accordance with an increase of tool wear and the values of thrust force have increased almost 7 times for about two minutes of tool operation.

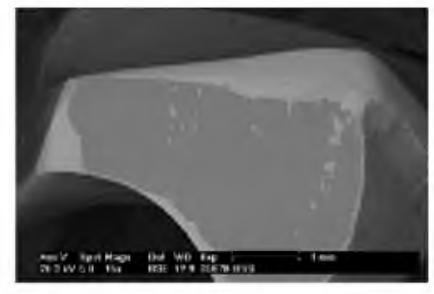

a

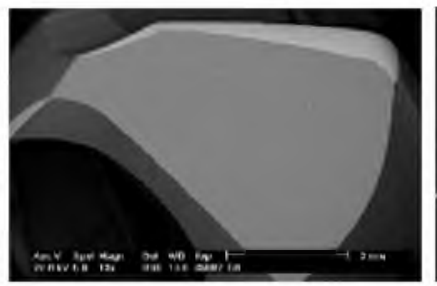

b

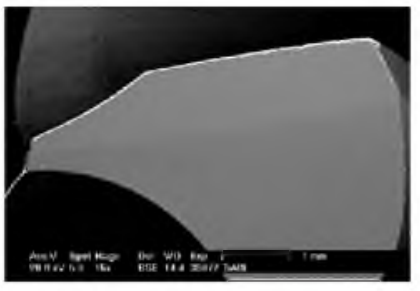

$\mathrm{c}$

Fig. 3. Tool wear of non-coated drill, $v_{c}=31.7 \mathrm{~m} / \mathrm{min}$ (a), coated drill, $v_{c}=35.2 \mathrm{~m} / \mathrm{min}$ (b), and coated drill, $v_{c}=56.5 \mathrm{~m} / \mathrm{min}$ (c).

The wear of the coated solid carbide drill was stable at the value of $V B=0.12 \mathrm{~mm}$ after the first stage of growing for a relatively short time. It stayed without any remarkable changes for more than five minutes $(317 \mathrm{~s})$ of work, in spite of the fact, that this drill had operated at a higher cutting speed $\left(v_{c}=56.5 \mathrm{~m} / \mathrm{min}\right.$, Fig. $\left.3 \mathrm{c}\right)$ in comparison with high-speed steel drills $\left(v_{c}=31.7-35.2 \mathrm{~m} / \mathrm{min}\right.$ ). It could be expected that the solid carbide drill wear will not be increase considerably regardless of the operation time over the next few minutes. The values of torque and thrust force especially are growing very slowly due to the tool wear for the solid carbide drill.

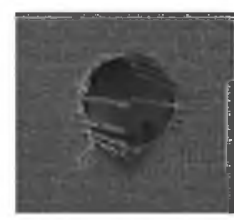

a

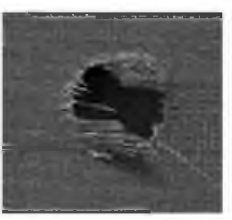

b

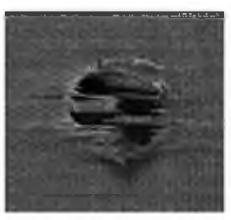

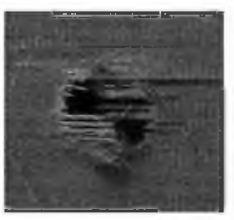

d

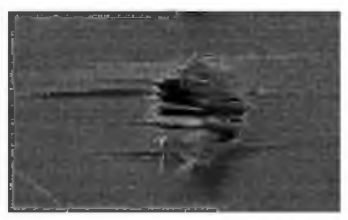

Fig. 4. Dependence of delamination on tool wear for different: values of facet width at the drill major flank $V B$ : 0.12 (a), 0.26 (b), 0.39 (c), 0.60 (d), and $0.77 \mathrm{~mm}$ (e).

For any tool material type used, it is important to secure sharp cutting edge. When a tool starts to lose its sharpness, it tends to pull and unwind fibers from the drilled parts instead of cutting them. In addition, excessive tool wear causes increase of thrust force and consequent delamination. Hence, the cutting tool must be changed before wear occurs. The dependence of delamination on tool wear is shown in Fig. 4a-e. The 
unidirectional reinforced carbon/epoxy laminate, fabricated by hand lay-up technique from prepreg was used for test (total thickness $6 \mathrm{~mm}$, thickness of one layer $0.15 \mathrm{~mm}$ ). The holes of $6 \mathrm{~mm}$ in diameter were drilled by high-speed steel drill (clearance angle $\alpha_{f}=13^{\circ}$, point angle $2 \kappa_{r}=118^{\circ}$ ), cutting speed $v_{c}=30.2 \mathrm{~m} / \mathrm{min}$, feed per revolution $f=0.1 \mathrm{~mm}$.

Surface Quality. The typical appearance of the drilled hole surfaces are shown in Fig. 5a (along the fibers' axes) and Fig. 5b (perpendicularly to the fibers axes) for the GFRP drilling. The hole had been machined with a coated solid carbide drill of diameter $D=10 \mathrm{~mm}$ at cutting speed $v_{c}=56.5 \mathrm{~m} / \mathrm{min}$ and feed per revolution $f=0.20 \mathrm{~mm}$. The hole axis is oriented horizontally in both of these figures. It is evident, that reinforcing fibers fail by brittle fracture mechanism under tensile stress (Fig. 5a) and shear stress (Fig. 5b). Close-up view of brittle fracture of glass fiber is shown in Fig. 5c. The bond between fibers and matrix is damaged and a large amount of micro-particles is created from fibers and matrix. Surface roughness is maximum when the fibers are loaded compressively at $45^{\circ}$ angle. With the convention of Fig. 2, where the arrow indicates the direction of tool rotation, surface roughness is maximum at 135 and $315^{\circ}$, and in this position the torque applied is maximum. The same observation was reported by other investigators [2].

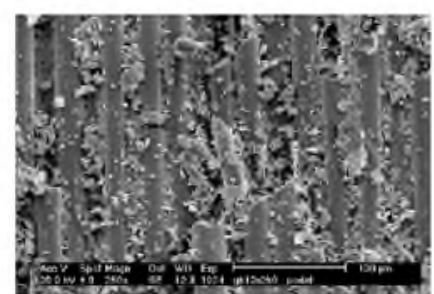

a

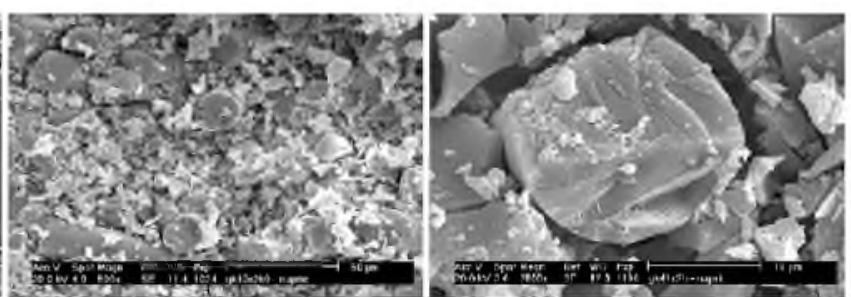

$\mathrm{b}$

C

Fig. 5. Drilled hole surfaces: along (a) and perpendicularly (b) to the fibers' axes and close-up view of brittle fracture of glass fiber (c).

Conclusions. An analysis of delamination damage caused by thrust force (feed force) of twist drill at the exit plane has been provided. The critical thrust force for crack propagation is a function of uncut thickness $h$ and material properties of machined composite materials. To avoid delamination, the thrust force of drill should not exceed this value. Hence, the feed rate should be reduced and usage of a drill with short chisel edge and sharp cutting edge is recommended. The chisel edge generates over than $50 \%$ thrust force, and worn drills with $V B=1.33 \mathrm{~mm}$ can increase thrust force by 7 times, as shown experiment. The reinforcing fibers are the main reason of tool wear in drilling of composites, particularly in case of high-speed steel drills. The surface roughness of drilled holes is maximum when the fibers are loaded compressively at $45^{\circ}$ angle.

1. H. Zhang, W. Chen, D. Chen, and L. Zhang, Key Eng. Mater, 196, 43-52 (2001).

2. S. Abrate, in: P. K. Mallick (Ed.), Composites Engineering Handbook, Ch. 15, Marcel Dekker Inc. (1997).

3. M. Ozaki, Supervisory Control of Drilling of Composite Materials, University of California. Berkeley.

4. H. Hocheng and C. C. Tsao, J. Mater. Proc. Technol., 140, 335-339 (2003).

5. G. Spur and U. Lachmund, in: S. Jahanmir, M Ramulu, and P. Koshy (Eds.), Machining of Ceramics and Composites, Ch. 7, Marcel Dekker Inc. (1999). 